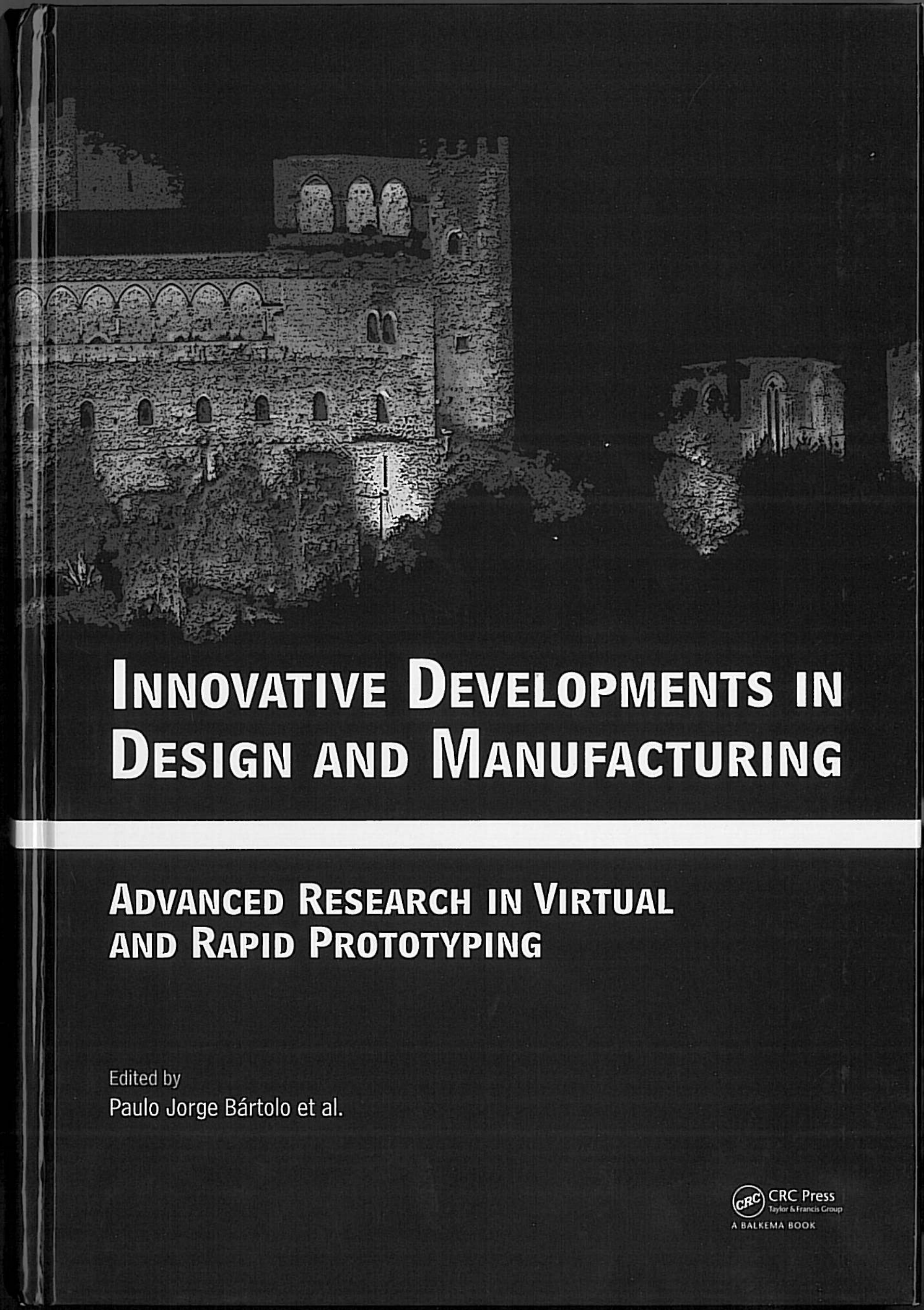


INNOVATIVE DEVELOPMENTS IN DESIGN AND MANUFACTURING 


\section{Innovative Developments in Design and Manufacturing}

\section{Advanced research in virtual and rapid prototyping}

\section{Editors}

Paulo Jorge da Silva Bártolo

Ana Cristina Soares de Lemos

António Mário Henriques Pereira

Artur Jorge dos Santos Mateus

Ausenda Luís Avelar Mendes

Carla Sofia Monteiro de Moura

Carlos Alexandre Bento Capela

Catarina Sofia Gaspar da Silva

Flávio André Carvalho Domingues

Helena Maria Coelho da Rocha Terreiro Galha Bártolo

Henrique de Amorim Almeida

Irene Sofia Carvalho Ferreira

João Manuel Matias

Nuno Manuel Fernandes Alves

Susana Cristina Serrano Fernandes Rodrigues

Centre for Rapid and Sustainable Product Development

Polytechnic Institute of Leiria, Portugal 
CRC Press/Balkema is an imprint of the Taylor \& Francis Group, an informa business

C 2010 Taylor \& Francis Group, London, UK

Typeset by Vikatan Publishing Solutions (P) Ltd., Chennai, India

Printed and bound in Great Britain by Antony Rowe (A CPI Group Company), Chippenham, Wiltshire

All rights reserved. No part of this publication or the information contained herein may be reproduced, stored in a retrieval system, or transmitted in any form or by any means, electronic, mechanical, by photocopying, recording or otherwise, without written prior permission from the publisher.

Although all care is taken to ensure integrity and the quality of this publication and the information herein, no responsibility is assumed by the publishers nor the author for any damage to the property or persons as a result of operation or use of this publication and/or the information contained herein.

Published by: CRC Press/Balkema

P.O. Box 447, 2300 AK Leiden, The Netherlands

e-mail: Pub.NL@taylorandfrancis.com

www.crcpress.com - www.taylorandfrancis.co.uk - www.balkema.nl

ISBN: 978-0-415-87307-9 (Hbk)

ISBN: 978-0-203-85947-6 (Ebook) 


\section{Table of contents}

Preface

Sponsors

International scientific committee

\section{Invited lectures}

New challenges for Reverse Engineering in facial treatments: How can the new 3-D non invasive surface measurements support diagnosis and treatment?

L.M. Galantucci

\section{Biomanufacturing}

Scaffold micro-architecture optimization based on bio-mimetic principles

A minibioreactor for developing "perfused" capillaries in cardiomyocyte aggregates

C.K. Chua, D. Liu, K.F. Leong, V. Mironov \& V. Kasyanov

Spinning of biomaterial microfibers for tendon tissue engineering

C.K. Chua, J. An, K.F. Leong, C.M. Cheah \& H. Chang

Stereolithographic rendering of low molecular weight polymer scaffolds

for bone tissue engineering

D. Dean, J. Wallace, K. Kim, A.G. Mikos \& J.P. Fisher

Process flow for designing functionally graded tissue engineering scaffolds

C.K. Chua, N. Sudarmadji, K.F. Leong, S. M. Chou, S. C. Lim \& W.M. Firdaus 
Rapid Prototyping models of foetuses built from Ultrasound

3D and Magnetic Resonance files

J.R.L. Santos, J.R.L. Santos, R.C. Fontes, S. Campbell \& H. Werner

A Computer Aided Design (CAD) support tool for parametric design

of products for Rapid Manufacture (RM)

P.C. Smith \& A.E.W. Rennie

Comparison of CT and CBCT for fabrication of dentistry models

via rapid prototyping technology

H. Kheirollahi, F. Abesi \& S. Rahmati

Global approach to design and manufacture Direct Parts

J. Kerninon, P. Mognol \& J. Y. Hascoët

Novel methodology in design of custom-made hip prosthesis

F. Abbaszadeh, S. Rahmati, F. Farahmand \& R. Fatollahzadeh

Use of BioCAD in the development of a growth compliant prosthetic

device for cranioplasty of growing patients

D.T. Kemmoku, P. Y. Noritomi, F. G. Roland \& J.V.L. da Silva

Artificial teeth manufacturing: Inspection of mould and teeth

by contactless scanning systems

E. Atzeni, L. Iuliano, P. Minetola, A. Salmi \& A. Gatto

Guided dental surgery based on integrating 3D image slicing and structured light scanning

S. Barone, A. Paoli \& A. V. Razionale

A robotic system for 3D optical scanning of large surfaces

M. Maggini, S. Barone, A. Paoli \& A.V. Razionale

A simple photogrammetric system for automatic capture and measurement

of facial soft tissues during movement

L.M. Galantucci, F. Lavecchia \& G. Percoco

3D digitation of museum sculptures for model-making purposes: Difficulties

and possible solutions

G. Celani, L. Cancherini, A. Jardini, M. Oliveira, J. V.L. da Silva \& V. Piccoli

The use of technologies as Rapid Prototyping and scanner inspection

in surgical planning to medical application

C.B.L. Ulbrich, H.A. Hermini \& C.A.C. Zavaglia

Performance evaluation of non contact measuring systems considering bias

M. Cavallaro, G. Moroni \& S. Petrò

A surgical training model manufacture using rapid prototyping technology

Image based modeling and morphological analysis of the human knee

G. Renner \& L. Hajder

Design of customised bioceramic medical implants by layered manufacturing

S.F. Khan \& K. W. Dalgarno

Reverse Innovative Design in Rapid Modelling and Reverse Engineering industrial applications A.E. Sonn \& D. M. Dimitrov

3D-Digitalization of ankle movement and 3D-CAD-method for patient specific external ankle support development and Rapid Manufacturing R. Björkstrand, J. Tuomi, M. Paloheimo, J. Lindahl \& J. Salo 


\section{Preface}

"Innovative developments in design and manufacturing", contains papers presented at the 4th International Conference on Advanced Research in Virtual and Physical Prototyping (VR@P 2009), held by the Centre for Rapid and Sustainable Product Development, Polytechnic Institute of Leiria, Portugal. The Centre for Rapid and Sustainable Product Developed is a centre of excellence hosted by the Polytechnic Institute of Leiria. Its mission is to contribute to the advancement of science and technology leading to more suitable, effective and efficient products, materials and processes, helping to generate added-value for Industry, and to promote the awareness of the role and importance of rapid and sustainable product development in society.

The International Conference on Advanced Research in Virtual and Physical Prototyping was designed to be a major forum for the scientific exchange of multi-disciplinary and inter-organisational aspects of virtual and rapid prototyping and related areas, making a significant contribution for further development of these fields. It joined participants from more than 20 countries. Such diversity was parallel to the various multi-disciplinary contributions to the conference, whose subjects enclose a wide range of topics like biomanufacturing, micromanufacturing, materials, advanced rapid prototyping technologies, rapid tooling and manufacturing, collaborative design and engineering, CAD and 3D data acquisition technologies, all of them making a significant contribution for future development. This research community has been strongly engaged in the development of innovative solutions to solve Industry's problems, contributing to a more pleasant and healthy way of living. I hope that this Conference has been truly worthwhile and this book can represent a significant contribution to research in the field of virtual and physical prototyping.

I am deeply grateful to authors, participants, reviewers, the International Scientific Committee, Session chairs, student helpers and Administrative assistants, for contributing to the success of this conference. The conference was endorsed by:

- The Polytechnic Institute of Leiria (IPL)

- The Centre for Rapid and Sustainable Product Development (CDRsp)

- Portuguese Foundation for Science and Technology

- The International Academy for Production Engineering (CIRP)

- The Global Alliance of Rapid Prototyping Associations (GARPA)

- The Rapid Manufacturing Platform

Paulo Jorge da Silva Bártolo Conference Chairman Leiria, October 2009 


\title{
A surgical training model manufacture using rapid prototyping technology
}

\author{
Luís Queijo, João Rocha, Luísa Barreira \& Tiago Barbosa \\ Instituto Politécnico de Bragança, Bragança, Portugal \\ Paulo Miguel Pereira \\ Serviço de Neurocirurgia do Hospital de S. João, Porto, Portugal
}

Manuel San Juan

ESTII - Universidad de Valladolid; CIBER - Centro de Investigación Biomecánica y Ergonomía, Valladolid, Spain

\begin{abstract}
The use of rapid prototyping has increasingly begun to reveal itself as a tool of great value in supporting medical activity. From two-dimensional medical images from computed tomography (CT) or magnetic resonance imaging (MRI) it is possible to obtain three-dimensional models. The models produced by rapid prototyping technologies are useful both in educational and medical-surgical environments. It can simplify the diagnosis of certain diseases, the development of complex surgical procedures, the prostheses and medical devices manufacture and the visualization of anatomical structures in educational environment
\end{abstract}

\section{INTRODUCTION}

In this study we will present Rapid Prototyping (RP) used as a tool to manufacture a biomedical solid model from a human spine with Lytic Spondylolisthesis pathology for pre-surgical study procedures.

It is meant to do 3D reconstruction of a biomedical model from a 2D image file obtained from Computerized Tomography (CT) scan. After this reconstruction, Rapid Prototyping technology - Three Dimensional Printing (3DP or TDP) is used to produce the solid model.

\subsection{Lytic Spondylolisthesis}

The term spondylolisthesis refers to the slippage of a vertebra (and the spine above it) relative to the vertebra below. There are several aetiologies but the lytic or isthmic type is the most common. In a lytic spondylolisthesis there is a bilateral defect of the isthmus (pars interarticularis), which is the least resistant region of the posterior arch of the vertebra. The stress placed on this region by bipedal posture and loadings in extension may cause a fatigue (stress) fracture of the isthmus. With this fracture the vertebral body, pedicle and superior articular processes become separated from the inferior articular processes and hence from the vertebra below. This condition creates the possibility of slippage between the vertebrae.

The slippage between the vertebrae can cause the exiting nerve roots (the nerves exiting the spinal canal at this level, through the intervertebral foramina) to be squeezed causing leg pain and difficulty walking. When this occurs, a surgical treatment may be necessary to decompress the nerves and stabilize the spinal segment (to avoid further slippage) with or without reduction of the deformity.

\subsection{CT images conversion to $3 D$ models}

In the conversion process of a computerized tomography in to a 3D model, it is needed a sequence of cross sections from the studied object. Using a 3D reconstruction software it is possible to transform these bi-dimensional images in a three-dimensional model that can be used to produce a solid model in rapid prototyping equipment (Foggiatto 2006).

Images obtained from computerized tomography obey to the international standards from DICOM (Digital Imaging and Communications in Medicine) pattern. Those are obtained from axial cuts of the study area and the equipment should be settled to the less possible thickness, as the lower this value is, the better will be the model quality (Foggiatto 2006).

\subsection{Rapid prototyping and some medical applications}

Rapid Prototyping is the automated manufacture of physical objects. It is an addictive-constructive process, layer by layer that allows complex form objects direct production from three-dimensional data used to manufacture solid prototypes (Rocha \& Alves 2000). The geometries needed can be obtained using some CAD software or obtained through the conversion of data proceeding from 3D Scanners, Computerized Tomography or Magnetic Resonance devices. The first techniques of Rapid Prototyping become available in the eighties and were used to 
produce models and prototype parts (Alves \& Braga 2001).

One of the main applications of Rapid Prototyping is the fast way that is allowed in verifying new concept projects in the earlier stages or even in advanced phases of conception. In all Rapid Prototyping processes, a 3D CAD model is used that is translated into an STL (Stereolithography) format file, (Souza et al. 2003) where all the model surfaces are converted in a triangle mesh.

In Biomedical Engineering field, using Rapid Prototyping techniques it is possible to produce several types of anatomical models and implant replica with educational purposes or to better understand a specific patient pathology. The models, depending of available techniques, can be made of paper, wax, ceramic, plastic or metal (Antas \& Lino 2008). These models can be produced without finishing or color or have these finishing operations done later to improve visualization. For educational purpose it is possible to manufacture implant replica with much lower cost than the implant value.

A great interest can be found in anatomical models manufacture from patient tomographic images. These models allow students from biomedical field to have an easier view of a specific pathology and compare it with normal anatomical models. To better understand image techniques and anatomy, it is also possible to simultaneously compare the original image (TC or MRI) and 3D solid model.

Medical professionals cooperate with other field professionals to optimize pre-surgical pathology analysis, shorten surgical times, create personalized tools, facilitate the communication with patients and, simultaneously, to explore the capabilities this technology offers in personalized prosthesis design (Antas \& Lino 2008).

Vertebral Spine replica are particularly useful to diagnose, plan and simulate surgical procedures as it also allows the patients to understand the nature of their pathologies as well the need for surgical procedures (Madrazo et al. 2008)

Several manufacturing processes are available today, as Fused Deposition Modeling (FDM), Stereolithography (SLA), Selective Laser Sintering (SLS), Tridimensional Printing (TDP or 3DP) and Laminated Object Manufacturing (LOM) among other specific processes.

A brief description of the most used Rapid Prototyping processes is presented as follows:

- Fused Deposition Modeling (FDM): This prototyping process build the prototypes by depositing an extruded thermoplastic material. The injection head draw transversal section perimeters and fills them building, this way, each layer. The most used material is $\mathrm{ABS}$ once it has good mechanical properties. More recently have been developed equipments that allow the used of materials such as polycarbonate and polyphenilsulfone (PPSU) that have better mechanical and thermic properties than ABS.

- Stereolitography (SLA): This system builds the prototype by polymerizing a photosensitive liquid resin by applying an ultraviolet light formed by a laser. The solidifying process is made layer by layer, allowing obtaining a good surface finished prototype.

- Selective Laser Sintering (SLS): This process allows physical models building by using dust materials like ceramics or metal. These materials are processed in an inert and thermally controlled environment inside a chamber. In here, the melting point (sintering) is achieved by action of a $\mathrm{CO}_{2}$ laser. After one layer being sinterized, another layer is deposited until the prototype is finished. This method demands a post-processing work to obtain a better surface.

- Three Dimensional Printing (TDP or 3DP): In this process, models are built from a dust material (which can be a blend using materials like composite, cellulose among others) infiltrated with a liquid binder. This binder is applied through a printing head as used in traditional printing. The prototype is removed having the dust blended with the binder and needing operations of cleaning and medium consolidation.

- Laminated Object Manufacturing (LOM): In LOM, most of the times, the models are obtained by gluing successive layers of paper which are cut by a laser beam. All the paper not used in the model is cut in square or rectangle forms to make easier prototype remove. To ensure the needed rigidity a frame is also built. Model definition will result from paper thickness and quality. Sometimes, instead paper there can be, also, used glass fibres, ceramics or metal (Alves \& Braga 2001).

\section{METHODOLOGY}

After patient's authorization for TC images be used, these where transferred to the computer where would be done image processing and removed all personal information data.

The process to obtain the anatomic model is composed by the following steps:

- Pre-processing from bi-dimensional images and reconstruction from the surface between the contours is done in image processing software ScanIP®. This step is done by using image processing operation such as threshold, floodfill and paint, which allow the creation and distinction of the masks, based in image grey levels. These masks can be defined 
through the color choice done by user allowing giving the desired contrast degree to the model for an easier visualization as well to enlighten the desired elements.
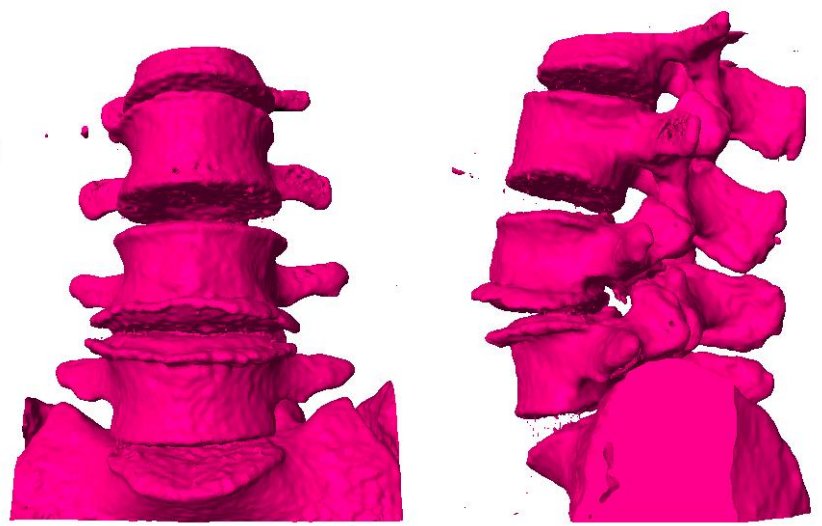

Figure 1. Image pre-processing done in ScanIP ${ }^{\circledR}$.

The first step of conversion consisted of 3D representation through the image processing application that allows closed volume visualization, after a segmentation operation based in the signal intensity - thresholding. This interactive application allow the user to detect and select contours in the spondylolistehesis area by doing a redefinition of grey levels that led to a separation of the bone from soft tissues. This operation applies gray levels recognition algorithms allowing, this way, a bigger grade of automatization.

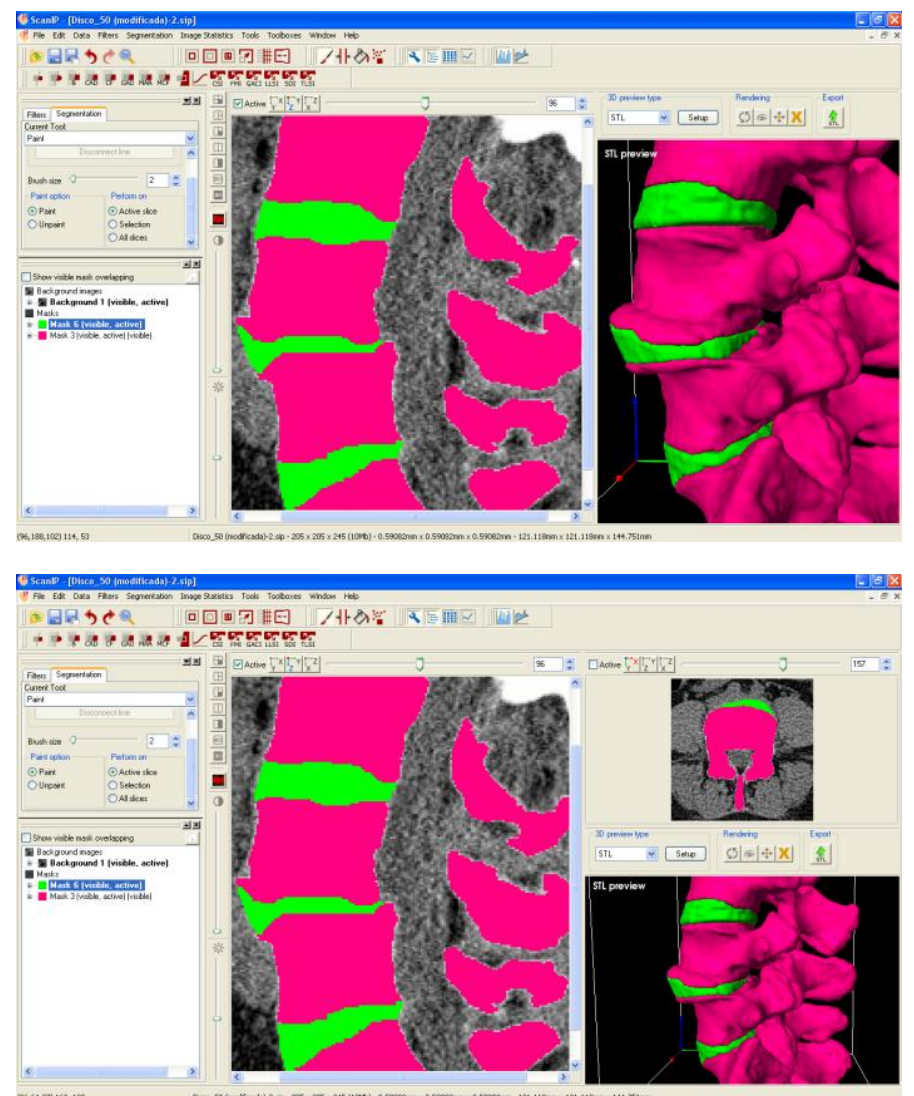

Figure 2. Images pre-processing done in ScanIP ${ }^{\circledR}$ software.
After obtaining the contours with the desired quality, those are enhanced in a manual way using paint and floodfill operations. These operations consist of adjusting the obtained contours to the shape of the elements intended to represent and model. This step is the most time consuming once the contours should be adjusted in more than one orientation (with axis changes) and in a manual way in each image to be processed.

- Rendering and 3D visualization allows to follow the work development during the previous step, to detect and correct possible imperfections. 3D rendering is done by the application of a consecutive planar triangle mesh from the masks defined in previous steps. Combining these two last phases it is possible to do an iterative process with the objective to present a model as close to the reality as possible.

By analyzing figures 1 and 3 it is possible to see the separation between masks corresponding to vertebrae bone tissue and intervertebral discs soft tissue. In figure 1 it is also possible to see model imperfection in a phase previous to manual masks adjustment.
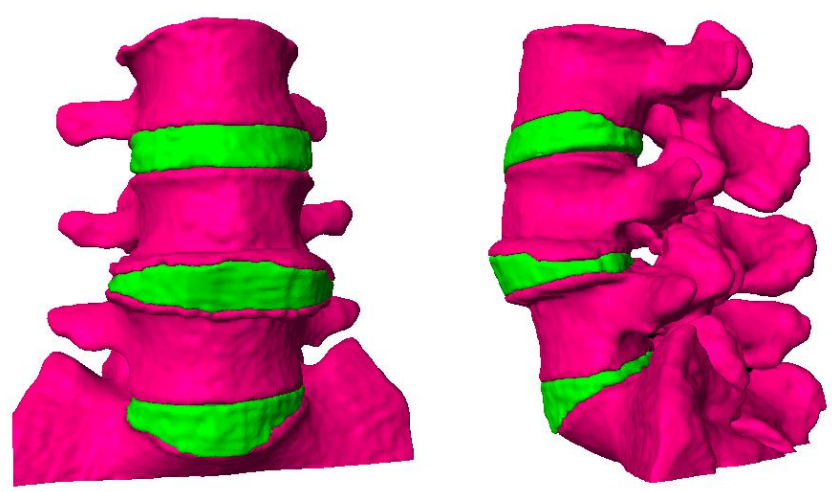

Figure 3. Rendering and 3D previewing in $\operatorname{ScanIP}^{(B)}$ software.

- STL (Stereolitography) data generation allows combining all the active masks in a single file or the creation of several files with distinct masks.

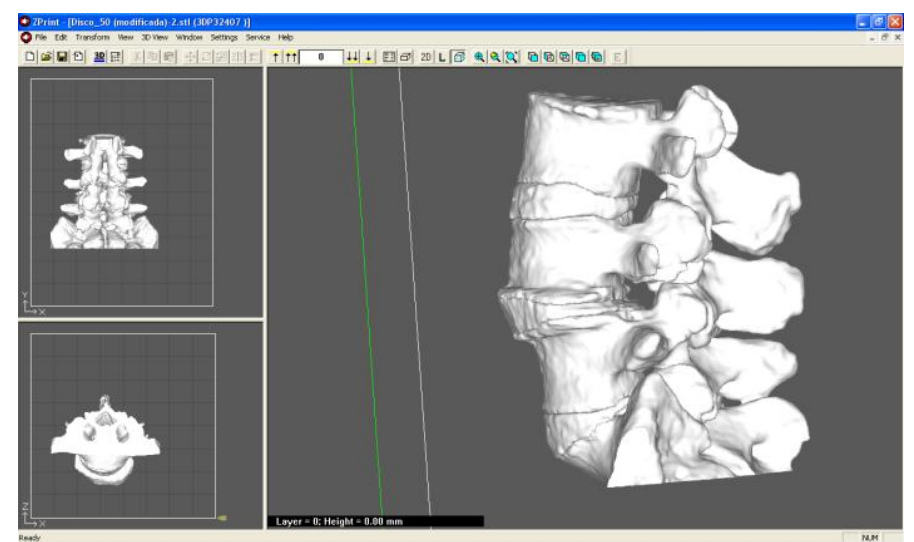

Figure 4. STL file visualization in printing software ZPrint ${ }^{\circledR}$. 
In this kind of files data consist of the conversion and translation from both the 3D model mesh outputted and the image processing software in to a printing format recognized by the rapid prototyping device. This format contains the model layer division allowing the layer by layer printing.

- Model manufacturing in Rapid Prototyping device Zprinter 310 from ZCorp.
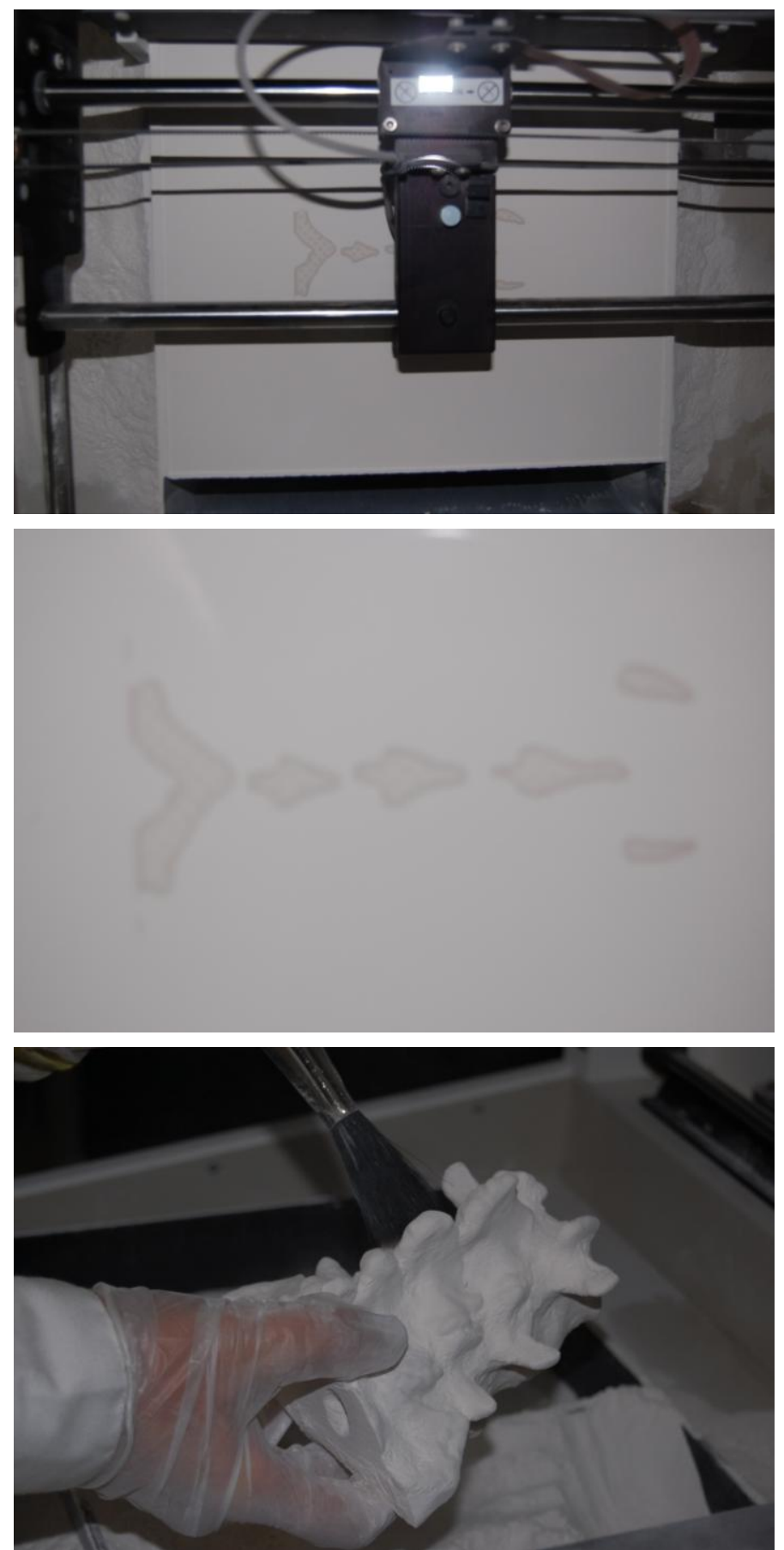

Figure 5. Complete model manufacturing.

In the images from figure 5 and 6 it is possible to visualize several phases of the manufacturing of a model, going from the layer impression until the cleaning of the residual dust.

- Finishing that includes removing and recycling of excess material and model material consolidation.
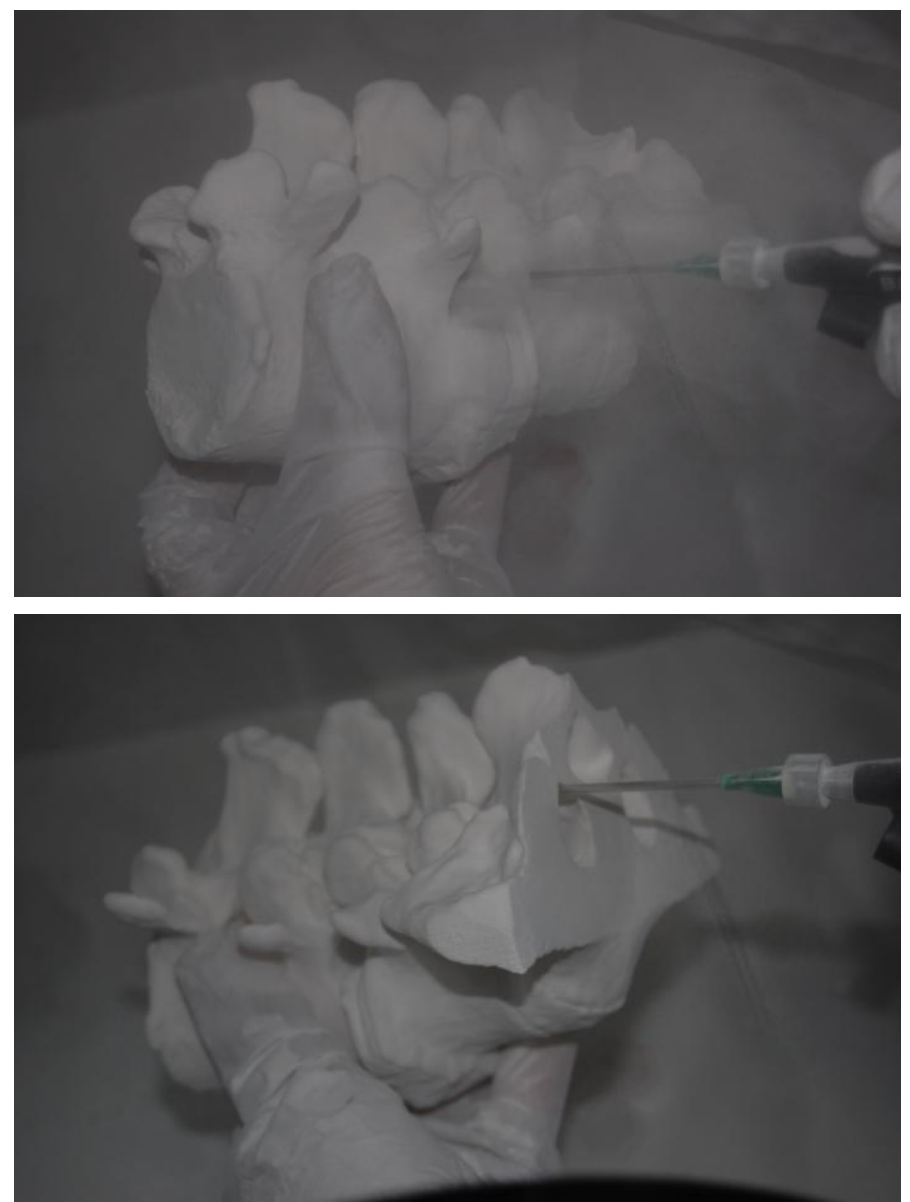

Figure 6. Cleaning and recycling operations.

Cleaning operations consist in the global remove, through compressed air action, of the non used dust to obtain an irregular but non dusty surface. After that, model surface consolidation is done by applying an epoxy resin or cyanoacrilate layer (Queijo \& Rocha 2009)

\section{CONCLUSIONS AND FURTHER WORK}

3D replicas of vertebral spine sections are useful in diagnosing, planning and surgery simulation. The visualization and the possible manipulation, by patients, from 3D replica allow them to understand their pathologies nature, surgical proceedings done by the surgeon as well to reduce anxiety facing surgery need.

With a multidisciplinary team cooperation it is possible to build, in a short period of time, vertebral spine section 3D models that fulfill all the requirements.

From represented models in Figure 7 it is possible to understand some pathology particularities. In our study model it can be shown a misalignment in the vertebrae and notice, even further, the slippage from one vertebra. Focusing the slippage region, it can also be noticed an estrangement from the spinal canal which cause nerve compression and all the symp- 
toms related to this pathology, like leg pain a walking difficulty.
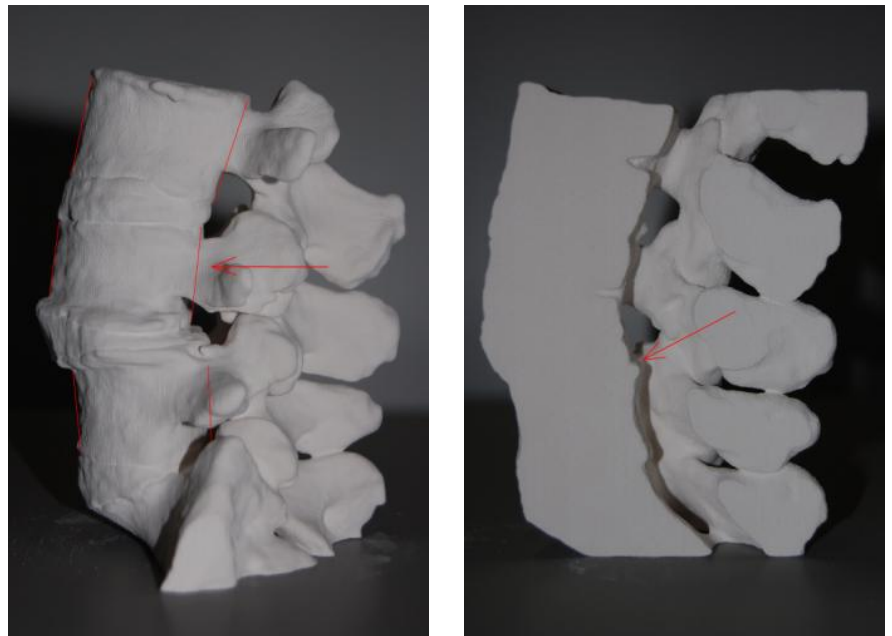

Figure 7. Problem areas highlighted in the printed models vertebra misalignment and spinal canal estrangement.

By showing this model to the patient he can understand the cause of his symptoms by comparing the two models shown above, and realize the need of actuate surgically to stabilize all that area, improving the well being of patients and avoiding further severe damages. On the other hand, the surgeon is able to start planning surgery by estimating the work to be done and by doing one first evaluation of the area he should intervene through this 3D replica model.
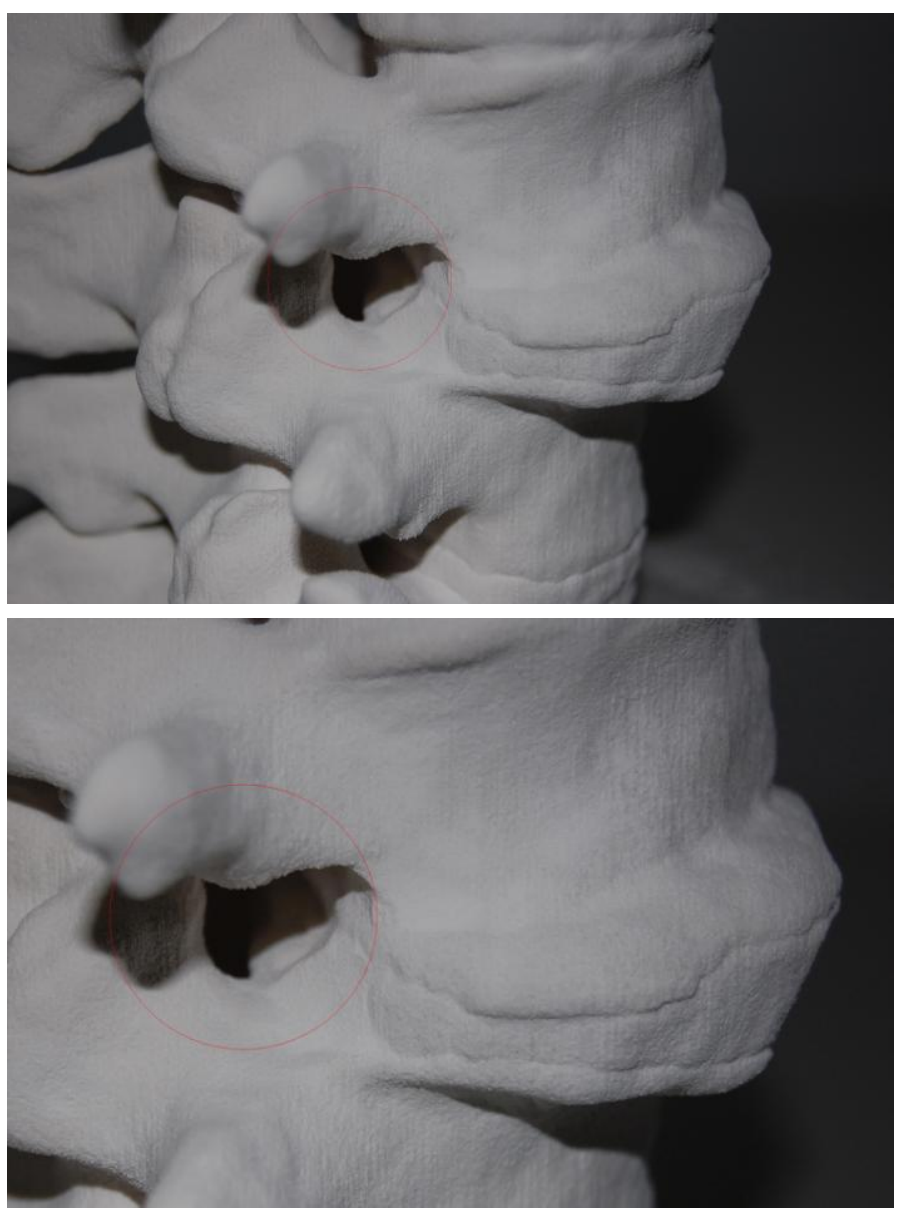

Figure 8. Estrangement in complete model and problem main area.
Further work will consist of 3D modeling of medical devices (screws, spacers and bars) and those will be inserted in the definitive positions assigned by medical staff allowing this way surgical planning.

Another model will be prototyped with vertebrae aligned due to medical devices application allowing the patient to get a better understanding of all surgical procedures and to analyze which amount of displacement that vertebrae's new functional positions will lead.

\section{REFERENCES}

Alves, L. \& Braga, F. 2001. Protoclick, prototipagem rápida. Porto. Protoclick, INEGI.

Alves L. \& Rocha J. 2000. Desenvolvimento de moldações cerâmicas compósitas para o fabrico de ferramentas metálicas. O Molde.

Antas, A. F. et al. 2008. Utilização das Tecnologias de Prototipagem Rápida na Área Médica. 50 Congresso LusoMoçambicano de Engenharia. Maputo. Moçambique.

Arantes, J. A. A. 2006. Diretrizes do tratamento neurocirúrgico das espondilolisteses degenerativas da Sociedade Brasileira de Neurocirurgia. (Projeto Diretrizes da Sociedade Brasileira de Neurocirurgia)

Foggiatto, J. A. 2006. O Uso da Prototipagem Rápida na Área Médico-Odontológica. Tecnologia \& Humanismo. v1, p. 60-68. Curitiba. Brasil.

Madrazo, I., et al. 2008. Stereolithography in spine pathology: a 2-case report. Surgical Neurology.

Netto, A. C. S. et al. 2003. Prototipagem rápida: uma ferramenta de projeto para a redução do tempo de desenvolvimento e melhoria de qualidade de produtos. IV Congresso. Brasileiro Gestão e Desenvolvimento de Produtos. Gramado RS. Brasil.

Queijo, L. et al. 2008. A prototipagem rápida na modelação de patogenias. 3. ${ }^{\circ}$ Congresso Nacional de Biomecânica. Bragança. Portugal.

Rocha, J. 2000. Moldações Cerâmicas Compósitas. FEUP. Porto. Portugal

Rocha, J. \& Alves, L. 2000. Utilização de moldações cerâmicas compósitas no fabrico de ferramentas metálicas. $2^{\circ}$ Encontro nacional do colégio de engenharia mecânica da ordem dos engenheiros. Coimbra. Portugal

Souza, M. A. et al. 2003. Integrando reconstrução 3D de imagens tomográficas e rototipagem rápida para a fabricação de modelos médicos. Revista Brasileira de Engenharia Biomédica, 19(2) p. 103-105. 